DOE / PC90308.5

$D E-F 622-90 P C 94368$

A NEW MODEL OF COAL-WATER INTERACTION AND RELEVANCE FOR DEWATERING

E. M. SUUBERG (PRINCIPAL INVESTIGATOR)

Y. YUN, W.D. LILIY (STAFF)

M. LANGNER ( STUDENT)

DIVISION OF ENGINEERING

BROWN UNIVERSITY

PROVIDENCE, RI 02912

TEL. (401) $863 \times 1420$

QUARTERLY TECHNICAL PROGRESS REPORT 1 SEPTEMBER, 1991- 30 NOVEMBER, 1991

PREPARED FOR:

U. S. DEPT. OF ENERGY

PITTSBURGH ENERGY TECHNOLOGY CENTER

P.O. BOX 10940

PITTSBURGH, PA 15236

DR. WU.WEY WEN

TECHNICAL PROJECT OFFICER

"US/DOE Patent Clearance is nes required prior to the publication of this document" 


\section{Proiect Overview}

This project is concerned with a basic scientific question co.acerning the properties of coal- to what extent is the ability of coal to hold moisture a manifestation of the well-known ability of coal to swell, when exposed to good solvents? The question implies that the longheld belief that coal holds a significant portion of its moisture by classical capillary condensation processes, is possibly in error. This seems to be a very real possibility for low rank coals- i.e. lignites. To explore this hypothesis further requires an examination of the basic phenomena governing the swelling of coals in good solvents. This is the focus of the first part of this projert.

The possibility that coal holds a significant portion of its moisture by solvent swelling mechanisms leads to an interesting technical issue. It is well known that simple drying of low rank coals at minemouth is ineffective because the process is reversible, to a significant degree. The economic advantages of pre-shipment drying have however dictated a search for "permanent" drying procedures. These have been developed by largely empirical means, and involve mild pyrolytic treatments of the coals in oil, steam or liquid water itself. The idea has always been to pyrolytically remove oxygen groups, which are assumed to be those that hold water most strongly by hydrogen bonding. The treatrnents have been designed to minimize tar formation and decrepitation of the particles, both highly undesirable. In relation to the present new hypothesis concerning water retention, it is likely that a sound approach to permanent drying would involve highly crosslinking the coal at mild drying conditions. The crosslinked coal could not swell sufficiently to hold much water. It is identifying processes to achieve this goal, that constinte the objective of the second phase of this work.

\section{Curreni Ouaree Summary}

This quarter's efforts involved further experiments using the flow microcalorimeter for 


\subsection{INTRODUCTION}

This report is, again, concerned with models of coal swelling in solvents. It is necessary to begin with a brief review of the classical solvent swelling theories of coals in order to illustrate the differences.

\subsection{The Classical Theory of Solvent Swelling of Coals}

The theory of solvent swelling in polymers (here used as models for coals) has been well

described elsewhere $1-4$. The starting point for all solvent swelling models is substantially the same, a statement that at swelling equilibrium, the Gibbs free energy of the system must be at a minimum. It is assumed that the change in the Gibbs free energy of the solvent-polymer system during swelling is made up of two contributions --one due to elastic deformation of the network, and the other due to mixing of the components. Thus

$$
\Delta \mathrm{G}=\Delta \mathrm{G}_{\mathrm{mix}}+\Delta \mathrm{G}_{\mathrm{el}}
$$

It has been noted that since the overall pressure-volume product does not change significantly during the swelling process, the above Gibbs free energies are roughly equivalent to Helmholtz free energies $\left(\Delta A_{\text {Inix }} \text { and } \Delta A_{e l}\right)^{3}$. Equilibrium is determined by the minimization of the free energy:

$$
\left(\partial \Delta \mathrm{G} / \partial \mathrm{n}_{\mathrm{S}}\right)_{\mathrm{T}, \mathrm{p}}=\left(\partial \Delta \mathrm{G}_{\mathrm{mix}} / \partial \mathrm{n}_{\mathrm{s}}\right)_{\mathrm{T}, \mathrm{p}}+\left(\partial \Delta \mathrm{G}_{\mathrm{e}} / \partial \mathrm{n}_{\mathrm{s}}\right) \mathrm{T}, \mathrm{p}_{\mathrm{p}}=0
$$

where $n_{S}$ is the number of moles of solvent imbibed into the network structure. It is in the details of calculating the individual contributions of mixing and elastic deformation that the well-known models of swelling differ from one another.

If the chains of the network are assumed to follow Gaussian statistics, the elastic free energy term for swelling a so-calied "phantorn network" (one in which the chains ane free to move through one another) is given by 2 :

$$
\Delta A_{e l}=(3 \xi R T / 2)\left[\left(1 / N_{c}\right)^{2 / 3-1]}\right.
$$

where $v_{c}$ is a measure of the nerwork deformation, equal to both the volume fraction of coal in 
the swollen network, and thus, the inverse of the volumetric swelling ratio of the coal. If the network deforms in an affine manner (meaning that the motion of the crosslink junctions is suppressed by the existence of neighboring chains), the comparable expression is 3,4 :

$$
\Delta A_{c l}=(3 v R T / 2)\left[\left(1 / v_{c}\right)^{2 / 3.1]} \cdot \mu k T \ln v_{c}\right.
$$

Real networks behave closest to the affine limit at low deformations, and the phantom limit at high. In both cases, the enthalpy change due to deformation of the network is assumed to be negligible. The expression (4) contains the controversial logarithmic term that Flory maintained should be present2, but which many authors do not include4.

The parameters $\xi, \mu$, and $v$ are used to characterize the network structure. $\xi$ is the cycle rank of the network, the number of independent circuits in the network or the number of "cuts" that would have to be made to reduce the network to a tree s'ructure with no closed cycles. The quantity $\xi$, on a molar basis, may be determined for a perfect network from 3 :

$$
\xi=\left(V_{O} \rho_{c} M_{c}\right)(1-2 / \phi)
$$

where $V_{0}$ is the initial volume of the sample, $\rho_{c}$ is the density of the unswollen sample, and $\mathrm{M}_{\mathrm{C}}$ is the molecular weight between crosslinks. A perfect network is defined as one with no dangling chain ends. It is probably a fair appraximation for coals, which have a highly crosslinked structure and few long sidechains. The parameter is the number of chains meeting at a junction. For crosslinking in a network, $\phi>2$. As compared to the case of ardinary polymers, in which is generally known, in the case of coals, the quantity is unknown. It is thought that the structure of coals probably involves chains of aromatic units, joined by aliphatic carbon, ether, or heteroatomic linkages. The crosslinks may then involve aromatic units that are simultaneously linked to two or more other such units, or from secondary or tertiary aliphutic carbons.

The parameter $v$ is the number of moles of network chains, and is relatod to $\xi$ through:

$$
v=\xi /(1-2 / \phi)=V_{0} \rho_{C} / M_{c}
$$

and $\mu$ is the number of moles of junctions in the network, and is given by:

$$
\mu=2 v / \phi
$$

The assumption of Gaussian chain statistics is likely to be poor in the case of a highly crosslinked network of fairly short chains. The Gaussian chain must have an end-to-end distance which is small, compared to its fully extended length. This will not be possible in rigidly crosslinked networks such as that of coal. Modifications to the Gaussian statistics have 
been suggested by both Kovac 6 and by Lucht and Peppas 5 . Kovac developed a modification of Gaussian statistics for freely-jointed short chains, using the three chain model and obtained:

$$
\Delta \mathrm{A}_{\mathrm{el}}=-\left(3 \mathrm{RT}^{\mathrm{p}} \mathrm{p}_{\mathrm{c}} \mathrm{V}_{0} \mathrm{~N} / 2 \mathrm{M}_{\mathrm{c}}\right)\left[\ln \left(1-\mathrm{v}_{\mathrm{c}}-2 / 3 / \mathrm{N}\right)-\ln (1-1 / \mathrm{N})\right]
$$

The parameter $\mathbf{N}$ introduced here is the number of repeat units in the chain between crosslinks:

$$
\mathrm{N}=\mathrm{M}_{\mathrm{C}} / \mathrm{M}_{\text {cluster }}
$$

where $M_{\text {cluster }}$ is the size of a basic repeat unit in the structure, and usually assumed to be constituted mainly of a fused aromatic ring cluster. The value of $\mathrm{M}_{\text {cluster }}$ is difficult to determine, and has been estimated from molecular weights to be characterized by values between 100 and 500 daltons.

Regardless of the elasticity model chosen, the criterion of swelling equilibrium is that given in (2), except that as noted above, it is assumed that $\Delta A_{\mathrm{el}}=\Delta \mathrm{G}_{\mathrm{el}}$. This then gives for the phantom network model, (3):

$$
\left[\partial\left(\Delta \mathrm{G}_{\mathrm{mix}} / \mathrm{RT}\right) / \partial \mathrm{n}_{\mathrm{s}}\right] \mathrm{T}, \mathrm{p}=-\left[(1-2 / \phi) \rho_{\mathrm{c}} \mathrm{V}_{\mathrm{s}} \mathrm{v}_{\mathrm{c}} 1 / 3 \mathrm{~V} \mathrm{M}_{\mathrm{c}}\right.
$$

For the affine model, (4):

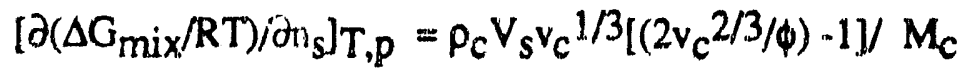

For the modified Gaussian model, (8):

$$
\begin{aligned}
& {\left[\partial\left(\Delta G_{\text {mix }} / R T\right) / \partial n_{s}\right] T, p }=-\rho_{c} v_{s} v_{c} 1 / 3 /\left[1-N^{-1} v_{c}-2 / 3\right] M_{c} \\
& {\left[\partial\left(\Delta G_{m i x} / R T\right) / \partial n_{s}\right] T_{, p}=-\rho_{c} v_{s} v_{c} 1 / 3\left[1+N^{-1} v_{c}{ }^{-2 / 3} y M_{c}\right.}
\end{aligned}
$$

where the latter approximation was suggested by the author 6 , and the former derived by us from (8).

W. The question of which elasticity model is correct remains a matter of considerable debate, but our fecling is that all are dsficient in at least one important respect. None includes a contribution from the dissociation of crosslinks in the coal. We are currently engaged in developing an expression of correct form. This effort will be grealy aided by the availability of elasticity data in the future.

The calculation of the free enerry of mixing normally follows the analysis by Flory2, based upon the liquid lattice theory. The free energy of mixing is modeled as being determined by two separate contributions, one due to the enthalpy of mixing, and the other due to the 
entropy of mixing. The overall expression for the free energy of mixing is:

$$
\begin{aligned}
\Delta G_{\text {mix }} & =\operatorname{RT}\left(n_{s} \ln v_{s}+\chi n_{s} v_{c}\right) \\
& =\operatorname{RT}\left(n_{s} \ln \left[1-v_{c}\right]+\chi n_{s} v_{c}\right)
\end{aligned}
$$

where the entropic contribution is embodied in the first term in parentheses, and the enthalpic in the second term. The coal-solvent interactions are assumed to be non-specific pairwise interactions (involving dispersion forces). The enthalpy of mixing ( $R T \chi n_{s}{ }^{v}$ ) would be positive (endothermic) for such non-specific interactions, and thus $\chi$ is normally a positive number. The value of $\chi$ is generally not known $a$ priori and is difficult to measure in the coal-solvent system. The use of (13), unmodified, in the evaluation of the partial molar free energy of mixing yields:

$$
\left.\left[\partial\left(\Delta \mathrm{G}_{\mathrm{mix}} / \mathrm{RT}\right) / \partial \mathrm{n}_{\mathrm{s}}\right]\right]_{\mathrm{T}, \mathrm{p}}=\ln \left(1-\mathrm{v}_{\mathrm{c}}\right)+\mathrm{v}_{\mathrm{c}}+\chi \mathrm{v}_{\mathrm{c}}{ }^{2}
$$

Substitution of (14) into an appropriate model derived from the elasticity equations will yield an expression in which $M_{c}$ is generally the only "unknown", since $v_{c}$ is normally obtained from solvent swelling data. It is for the purpose of estimating $M_{c}$ that this type of analysis has been routinely applied. Still, it must be noted that there are significant difficulties inherent in applying the theories because $\chi$ is generally not known ( and not really meaningful in the case of specifically interacting solvents, which include virtually all good solvents for coal). Also, as noted above, the elasticity models are probably inadequate. What is perhaps the only "safe" starting point is the assumption that one can approach the problem in the manner implied by equation (2), that is, by separating the calculation of elastic and mixing terms. There are even some doubts as to the legitimacy of doing this, but for the moment this is our starting point.

In an effort to obtain a better expression for the mixing term than that implied by equations (13) and (14), we assum: that the calculation of mixing entropy is correctly handled by the Flory theory. To improve upon the mixing enthalpy contribution, particularly for specifically interacting solvents (including water), we look to actual experimental results for guidance. The approach is to seck an empirical expression for the part of equation (14) that is currently represented by $\chi v_{c}{ }^{2}$. This is where experiments on the mixing enthalpy of coals and solvents are required, and we have turned to the flow microcalorimeter (see the previous quarterly). 


\subsection{MODIFICATIONS TO THE CLASSICAL THEORY OF SOLVENT SWELLING}

A difficulty in using the existing theories of solvent swelling is that they all assume that there are only two kinds of interactions possible in the coal network - covalent interactions (i.e. the covalent linkages between chain elements that are counted either as main chain linkages or crosslinks) and non-specific interactions between chain segments (i.e. van der Waals interactions). In the classical model, the solvent molecules substitute for the van der Waals interactions on a random (i.e. non-specific) basis, and the mixing enthalpy calculations effectively involve estimating the difference between solvent-solvent and solvent-polymer pairwise interactions (quantitatively characterized by the parameter $\chi$ in equation 13 above).

This viewpoint is inadequate for several reasons. First, the nature of specific interactions is such that exothermic mixing processes are certainly allowed. Also, specific mixing interactions involve, as the name implies, a non-random interaction of solvent with the macromolecular matrix. This in turn implies that there is a saturable limit to the number of such interactions possible, deternined by the number of specifically interacting groups in the network. A simple examiple might be a hydrocarbon polymer with a certain number of hydroxyl groups on the chain. In interaction with a polar solvent, the hydroxyl groups would probably be preferred sites for interaction. If there were not many such sites, then there would likeiy be a two-step type of behavior, in which the solvent first saturates the thermodynamically preferred sites, and then begins to fill in remaining non-specific interaction possibilities, to the limit dictated largely by entropic considerations. If the density of hydroxyl groups on the network is high enough, the two-step behavior might never be observed, as the swelling limit could be achieved merely by accommodating only the specific interactions. This would correspond to a case in which the classical theory is adequate, but for the fact that $\chi$ might be able to assume negative values, reflecting interactions other than simple van der Waals interactions.

There are yet further complications in application of the classical theory to coal networks. The first arises from the fact that, unlike the situation in polymer networks, there are many 
different types of interaction sites in coal, ranging from strongly acidic to strongly basic, in the general sense of Lewis acids and bases, i.e. electron acceptors and donors, respectively. In actuality, the broad spectrum of donor-acceptor interactions, as outlined by Gutmann ${ }^{7}$, is of relevance in this case. This spans the range of charge transfer processes, and includes the very important subset of hydrogen bonding interactions.

It is not the existence of a wide variety of possible acceptor-donor interactions between coals and solvents that presents the problem. Rather, it is the existence of the wide range of possible interactions coupled with the elastic nature of the coal network that is the origin of the downfall of all classic theories. There is a strong probability that many intemal charge transfer processes occur within the coal network, resulting in non-covalent crosslinks. In a solvent that is unable to dissociate some or all of such non-covalent crosslinks, the network behaves as though it were much more highly crosslinked than what would be the case if only covalent crosslinks were involved. This is presumably the origin of the unusually high values of crosslink density obtained from elastic properties of coal $^{8}$, and is consistent with coal's assuming rubbery properties at or below room temperature, if swollen in an appropriate solvent ${ }^{9}$.

Good solvents for coal are those that can disrupt the non-covalent interactions by substituting for one of the coal functional groups involved in the non-covalent bonding interaction. Generally speaking, strong nitrogen bases (i.e. good electron donors) have been the most effective swelling solvents, and there is thus a suggestion that there are strong electron donors present in the coal (there are known to be many nitrogen functional groups and probably basic oxygen groups as well). The variation of coal swellability with electron donor strength has been well demonstrated in a classic study, which also showed that the ordinary solubility parameter was wholly inadequare for correlating the data 10 .

The above leads one to the conclusion that the possibility of non-covalent crosslink dissociation should be included in an analysis of solvent swelling of coals. To not include this feature is to rule out any possibility of explaining the swelling behavior of coais with the full range of specifically interacting solvents. That is to say, the effective crosslink density in a strong electron donor solvent such as pyridine is lower than the effective crosslink density in a weaker donor solvent, such as propanol. The former swells coals significantly more than the latter, and this is quite possibly a manifestation of the inability of the propanol to dissociate 
non-covalent crosslinks as weil as does the pyridine. The alternative explanation has historically involved invoking differences in solubility parameter between coal and solvent (which would be felt through its effect on $\chi$ ), but this is clearly inadequate in this case, since the two solvents named have similar solubility parameters. The importance of including (or excluding) specific interaction effects in analysis of the swelling behavior of coals was recognized by Larsen and coworkers 11 .

A straightforward, albit crude, approach for including non-covalent crosslink dissociation in swelling models is as follows, using the modified Gaussian model of elasticity (8) as the starting point. Differentiation with respect to $n_{\mathrm{S}}$ yields:

$$
\begin{aligned}
{\left[\partial\left(\Delta G_{e l} / R T\right) / \partial n_{s}\right] T, p=} & {\left[1-v_{c}{ }^{-2 / 3} N^{-1}\right]^{-1}\left(v_{s} \rho_{c} v_{c}^{1 / 3} / M_{c}\right) } \\
& -\left(3 V_{0} \rho_{c} / 2 M_{c}^{2}\right)\left[\left(1-N^{-1}\right)^{-1}-\left(v_{c} 2 / 3-N^{-1}\right)^{-1}\right]\left(d M_{c} / d n_{s}\right)
\end{aligned}
$$

The variation of $\mathrm{M}_{\mathrm{c}}$ with solvent uptake is related to the number of crosslinks broken:

$$
\begin{aligned}
\left(d M_{c} / d n_{s}\right) & =\left(d M_{c} / d \mu\right)\left(d \mu / d n_{s}\right) \\
& =-\left(2 V_{O \rho_{c}} / 3 \mu^{2}\right)\left(d \mu / d n_{s}\right) \\
& =-\left(3 M_{c}^{2} / 2 V_{O \rho_{c}}\right)\left(d \mu / d n_{s}\right)
\end{aligned}
$$

Note that in this model, $\phi=3$ has been assumed. The term $\left(d \mu / d n_{S}\right)$ is related to the efficiency of crosslink disruption by solvent. Presumably, not every imbibed solvent molecule will dissociate a non-covalent crosslink. It is therefore assumed that $\left(d \mu / d n_{s}\right)=-f$, where $0 \leq f \leq 1$. The quantity $f$ may in fact be a function of $n_{S}$. This then leads to:

$$
\begin{aligned}
{\left[\partial\left(\Delta \mathrm{G}_{\mathrm{el}} / \mathrm{RT}\right) / \partial \mathrm{n}_{\mathrm{s}}\right] \mathrm{T}_{\mathrm{p}}=\mathrm{v}_{\mathrm{c}}{ }^{1 / 3}\left[1-\mathrm{v}_{\mathrm{c}}{ }^{-2 / 3} \mathrm{~N}^{-1}\right]^{-1}\left(\mathrm{v}_{\mathrm{s}} \rho_{\mathrm{c}} \mathrm{M}_{\mathrm{c}}\right) } \\
+(9 \mathrm{NN} / 4)\left[(\mathrm{N}-1)^{-1}-\left(\mathrm{Nv}_{\mathrm{c}} \mathrm{c}^{\left.2 / 3-1)^{-1}\right]}\right.\right.
\end{aligned}
$$

The case of $f=0$ (i.e. no bond dissociation) is identical with the result expressed in (12a) in which $\left[\partial\left(\Delta \mathrm{G}_{\mathrm{el}} / \mathrm{RT}\right) / \partial \mathrm{n}_{\mathrm{s}}\right] \mathrm{T}, \mathrm{p}=-\left[\partial\left(\Delta \mathrm{G}_{\mathrm{mix}} / \mathrm{RT}\right) / \partial \mathrm{n}_{\mathrm{s}}\right]_{\mathrm{T}, \mathrm{p}}$ has been assumed.

It has now been assumed that initially the coal contains covalent and non-covalent crosslinks. If $\mu$ is the total number of crosslinks at any time, $\mu_{c}$ is the total number of covalent crosslinks (a constant), and $\mu_{n c}$ is the number of non-covalent crosslinks at any time ( a function of $n_{\mathbf{s}}$ ), then

$$
\mu=\mu_{c}+\mu_{n c}=2 V_{O P} \beta M_{c}
$$

given the assumption of $\phi=3$, as is consistent with the Kovac three-chain model. This may be 
rearranged to give:

$$
\left(2 \rho_{c}\left(3 M_{c}\right)=\left(\mu_{c}+\mu_{n c}\right) N_{0}\right.
$$

The right hand side of (19) represents the total number of crosslinks per unit volume. Let the ratio of non-covalent crosslinks initially present to covalent crosslinks be r:

$$
r=\mu_{\mathrm{nc}, 0} / \mu_{\mathrm{c}}
$$

Then it may be seen that:

$$
\left(2 p_{c} / 3 M_{c 0}\right)=(1+r) \mu_{c} / V_{0}
$$

where $\mathrm{M}_{\mathrm{c} 0}$ is the initial molecular weight between effective crosslinks, both covalent and non-covalent. As solvent is added, crosslinks are dissociated and $M_{c}$ continually increases as dictated by $\left(d \mu / d n_{S}\right)=-f$. Making the assumption that $f$ is constant, (19) may be rewritten as :

$$
\begin{aligned}
\left(2 \rho_{\mathrm{c}} \mathrm{V}_{\mathrm{s}} / 3 \mathrm{M}_{\mathrm{c}}\right)=\left(\mu_{\mathrm{c}}+\mu_{\mathrm{nc}, 0}-\mathrm{fn}_{\mathrm{s}}\right) \mathrm{V}_{\mathrm{s}} \mathrm{N}_{0}=\left(\mu_{0}-\mathrm{fn}_{\mathrm{s}}\right) \mathrm{V}_{\mathrm{s}} \mathrm{V}_{0} & =\left(2 \rho_{\mathrm{c}} \mathrm{V}_{\mathrm{s}} / 3 \mathrm{M}_{\mathrm{c} 0}\right)-\mathrm{f} /\left(\mathrm{v}_{\mathrm{c}}{ }^{-1}-1\right) \\
= & (1+\mathrm{r}) \mathrm{V}_{\mathrm{s}} \mu_{\mathrm{c}} / \mathrm{V}_{0}-\mathrm{f} /\left(\mathrm{v}_{\mathrm{c}}{ }^{-1}-1\right) \\
& =(1+\mathrm{r}) \mathrm{V}_{\mathrm{s}}\left(2 \rho_{\mathrm{c}} 3 \mathrm{M}_{\mathrm{c}, \max }\right)-\mathrm{f} /\left(\mathrm{v}_{\mathrm{c}}{ }^{-1}-1\right)
\end{aligned}
$$

The initial value of $M_{c 0}$ and the value $M_{c, \max }$ (the molecular weight between crosslinks when all non-covalent crosslinks are broken) are unknown. 'The value $M_{c 0}$ is likely to be quite low, as supported by the calculations of $M_{c}$ from mechanical properties that give very low values ${ }^{8}$. The expression (20) can be rewritten as:

$$
M_{c}=M_{c, \max } /\left[1+r-\alpha f\left(v_{c}^{-1}-1\right)\right]
$$

where $\alpha=3 \mathrm{M}_{c, \max } / 2 \rho_{\mathrm{c}} \mathrm{V}_{\mathrm{s}}$. The quantity $\alpha$ is a constant for any coal/solvent pair. Finally, this expression may be used to obtain $\mathrm{N}$, as a function of extent of swelling, sinc: $\mathrm{N}=\mathrm{M}_{\mathbf{c}} \mathrm{M}_{\text {cluster: }}$

$$
N=\left[(1+\tau) / N_{\max }-\left(\alpha / N_{\max }\right) f\left(v_{c}-1-1\right)\right]^{-1}
$$

defining $(1+r) / N_{\max }=\gamma$ and $\left(\alpha / N_{\max }\right)=\beta$, then the expression for $N$ may be rewritten as:

$$
N=\left[\gamma-\beta f\left(v_{c}-1-1\right)\right]^{-1}
$$

The expression (17) may also be rewritten in terms of the same variable set:

$$
\begin{aligned}
{\left[\partial\left(\Delta \mathrm{G}_{\mathrm{e}} / \mathrm{RT}\right) / \partial \mathrm{n}_{\mathrm{S}}\right] \mathrm{T}, \mathrm{p}=(3 / \mathrm{L} \beta)\left[\mathrm{Nv}_{\mathrm{c}}-1 / 3-\mathrm{v}_{\mathrm{c}}^{-1}\right]^{-1} } \\
+(9 \mathrm{fN} / 4)\left[(\mathrm{N}-1)^{-1}-\left(\mathrm{Nv}_{\mathrm{c}} / 3-1\right)^{-1}\right]
\end{aligned}
$$

Note that there are effectively four variables $\left(\beta, \gamma, f\right.$, and $\left.v_{c}\right)$ needed to evaluate (24). Note too that the term $\left[(\mathrm{N}-1)^{-1}-\left(\mathrm{Nv}_{\mathrm{c}}{ }^{2 / 3}-1\right)^{-1}\right]<0$, for all realistic values of $\mathrm{v}_{\mathrm{c}}(\leq 1)$. This means that the effect of dissociation of crosslinks is to always decrease the partial molar free energy 
of elastic deformation, relative to the case of no dissociation.

There is a useful constraint on the choice of the variables in (24). In particular, $N$ can never exceed $\mathrm{N}_{\max }$. This implies from (22) that:

$$
1 \geq\left[(1+r)-\alpha f\left(v_{c}^{-1}-1\right)\right]^{-1}
$$

Rearranging:

$$
(\mathrm{Q}-1)=\left(\mathrm{v}_{\mathrm{c}}^{-1-1)} \leq\left(\gamma-\mathrm{N}_{\max }^{-1}\right) / \beta \mathrm{f}\right.
$$

where $\mathrm{Q}\left(=\mathrm{v}_{\mathrm{c}}{ }^{-1}\right)$ is the actually measured swelling ratio of the coal in a solvent. This means that beyond a certain predicted swelling ratio, all crosslinks have been dissociated, and the expression (24) must give way to one in which $f=0$.

Other bounds on the variables also suggest themselves. Since $r$ can be no less than zero, the lower limit of $\gamma$ is $I / N_{\max }$. The upper limit on $\gamma$ comes from the recognition that $N$ cannot be meaningfully less than unity, so that $\gamma$ itself will never be more than unity. In the case of $\beta$, if the density of coal is taken as $1.3 \mathrm{~g} / \mathrm{cc}$, then $\beta=1.15\left(\mathrm{M}_{\text {cluster }} / \mathrm{V}_{\mathrm{s}}\right)$. Aromatic cluster molecular weights cannot be less than one benzene ring ( 72 daltons), and solvents of interest typically do not have molar volumes in excess of about $130 \mathrm{cc} / \mathrm{mol}$. Thus $\beta$ will have a minimum value of order 0.6 . Clusters have been claimed to be as large as 500 daltons, and solvents as small as water $\left(V_{S}=18 \mathrm{cc} / \mathrm{mol}\right)$ are of interest, so the maximum value of $\beta$ could be as large as about 32 . Finally, $f$ can probably assume values only between zero and unity, assuming that one solvent molecule cannot dissociate more than one non-covalent crosslink.

It can also be noted that (26) implies certain values of the swelling number (see first quarterly), if it is assumed in this case that the swelling equilibrium happens to correspond to the situiation in which all crosslinks are just dissociated, and the swelling thus becomes more difficult. this condition is given by rearrangement of (26):

$$
\begin{aligned}
N_{S}=(Q-1) / N_{S} & =\left(\gamma-N_{\max }^{-1}\right) / \beta f V_{s} \\
& =3 \mathrm{r} / 2 \rho_{c} M_{\text {cluster }} \\
& =1.15 \mathrm{rf} / M_{\text {cluster }}
\end{aligned}
$$

If $\mathrm{M}_{\text {cluster }}$ is of order $10^{2}$, then the product (ri) must be near order unity, in order for swelling numbers to be of order $10^{-2}$ as earlier reported. This seems quite reasonable, as noted belcw.

An initial result of the theory is seen in Figure 1. In this figure are shown the calculations using (23), (24), and (26), as well as (14) for the frec energy of mixing. In the case of the 
free energy of mixing calculation, the value of $\chi$ was taken to be zero, in line with our earlier estimates of the heat effects during swelling (see last quarterly). These heat effects are thought to be quite small.

The figure shows the much lower free energy of elastic deformation that result when crosslink dissociation is included. The figure also shows the abrupt jump upward to the nondissociative elastic deformation curve when the criterion of (26) is reached. In this case, this jump immediately takes one to the equilibrium swelling criterion, at a reasomable value of about $Q=1.8$. Note that this behavior is predicted for a value of $\gamma=0.45$, before the completion of all dissociative processes, and requires a $\gamma=0.25$, when they are complete (since $r=0$ at the end, whereas it was 0.78 to start). The value of $N_{\max }$ implied by the fully dissociated case is 3.8. The parameter $f$ was taken to be 0.1 (i.e. one in ten solvents molecules imbibed breaks a crosslink) and $\beta=2.08$ is a reasonable value for propylamine.

Clearly much work needs to be done in the way of testing this model against many other data, but these initial results appear encouraging in terms of offering a model structure that at least presently seems much more reasonable for predicting the behavior of strongly interacting solvents, than have earlier theories.

\subsection{CONCLUSIONS}

A model of solvent swelling with crosslink dissociation has been developed. It can provide realistic swelling behavior for some simple cases of interest. Much work needs to be done to evaluate this model in the context of many existing data on solvent swelling. Its application to water swelling has not yet been attempted, because there are some uncertainties in how to handle certain mixing effects in this case.

\subsection{REFERENCES}

1 Flory,P.J.; Rehner,J. J.Chem.Phys. 1943, $11,521$.

2 Flory, P.J. Principles of Polymer Chemistry, Cornell Univ. Press, 1953.

3 Mark, J.E.; Erman, B. Rubberlike Elasticity A Molecular Primer, Wiley, New York, 1989. 
4 Treloar, L.R.G. The Physics of Rubber Elasticity, 3rd Ed., Clarendon Press, Oxford, 1975.

5 Lucht,L.M.; Peppas,N.A. in Chemistry and Physics of Coal Uitization (B.R. Cooper and L. Petrakis, Eds.), Am. Inst. of Physics, 1981, p.28.

6 Kovac, J. Macromolecules 1978, 11, 362.

7. Gutmann, V. The Donor-Acceptor Approach to Molecular Interactions, Plenum, New York, 1978.

8. Larsen. J.W.; Kovac, J. in Organic Chemistry of Coal (J.W. Larsen, Ed.), An. Chem. Soc. Symp. Ser. No. 71, 1978, p. 36.

9. Brenner, D. Fuel, 1984, 63, 132\%.

10. Szeliga, J.; Marzec, A. Fuel, 1983, $52,1229$.

11. Larsen, J.W.; Green, T.K.; Knvac, J. J. Org. Chem.,1885, 50, 4729. 
Figure 1. Partial Molar free energies for mixing and elastic deformation, propylamine solvent. This case used $f=0.1$, and $r=0.78, N_{\max }=3.8$.

$$
\beta=2.08, \gamma=0.45
$$

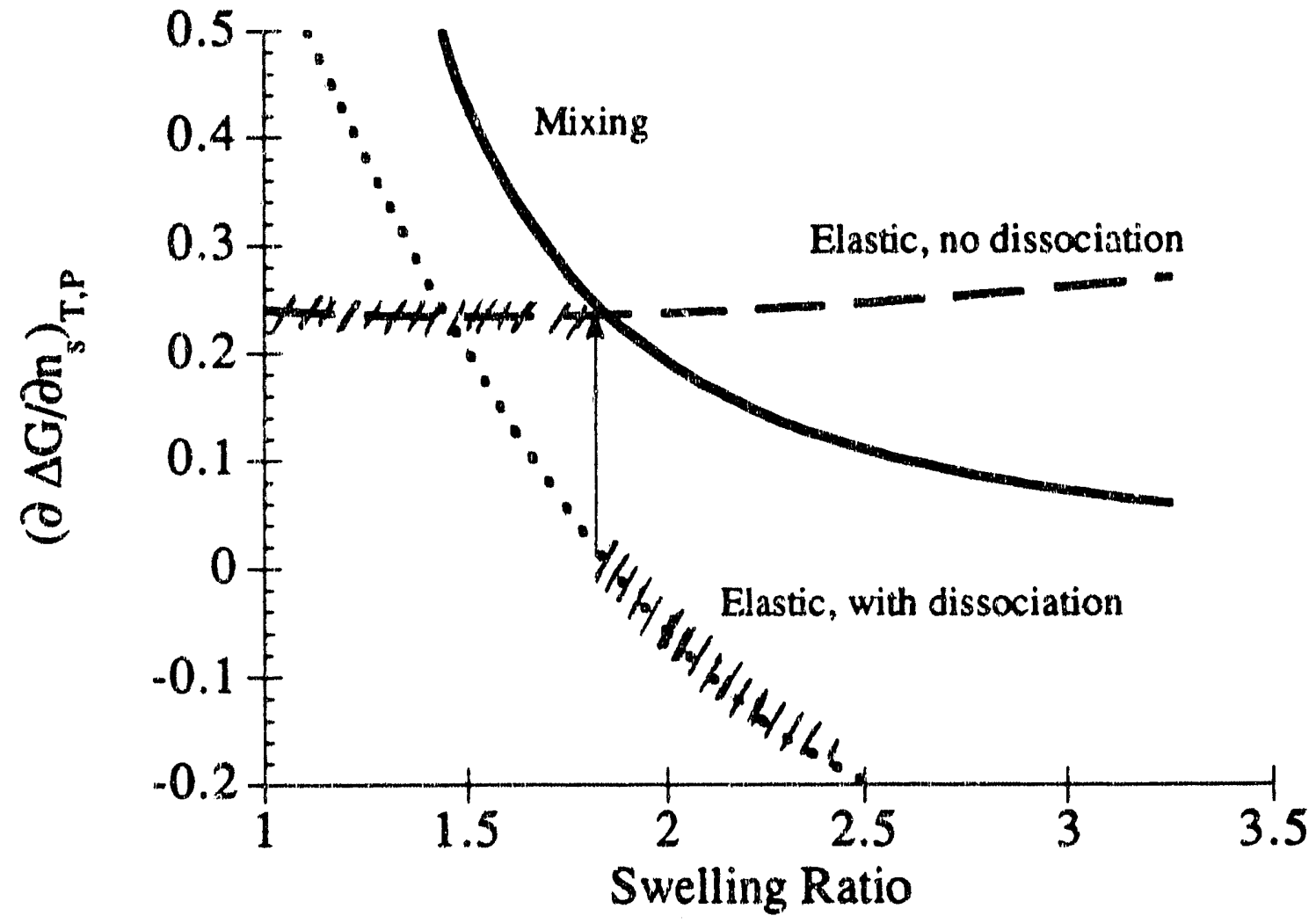



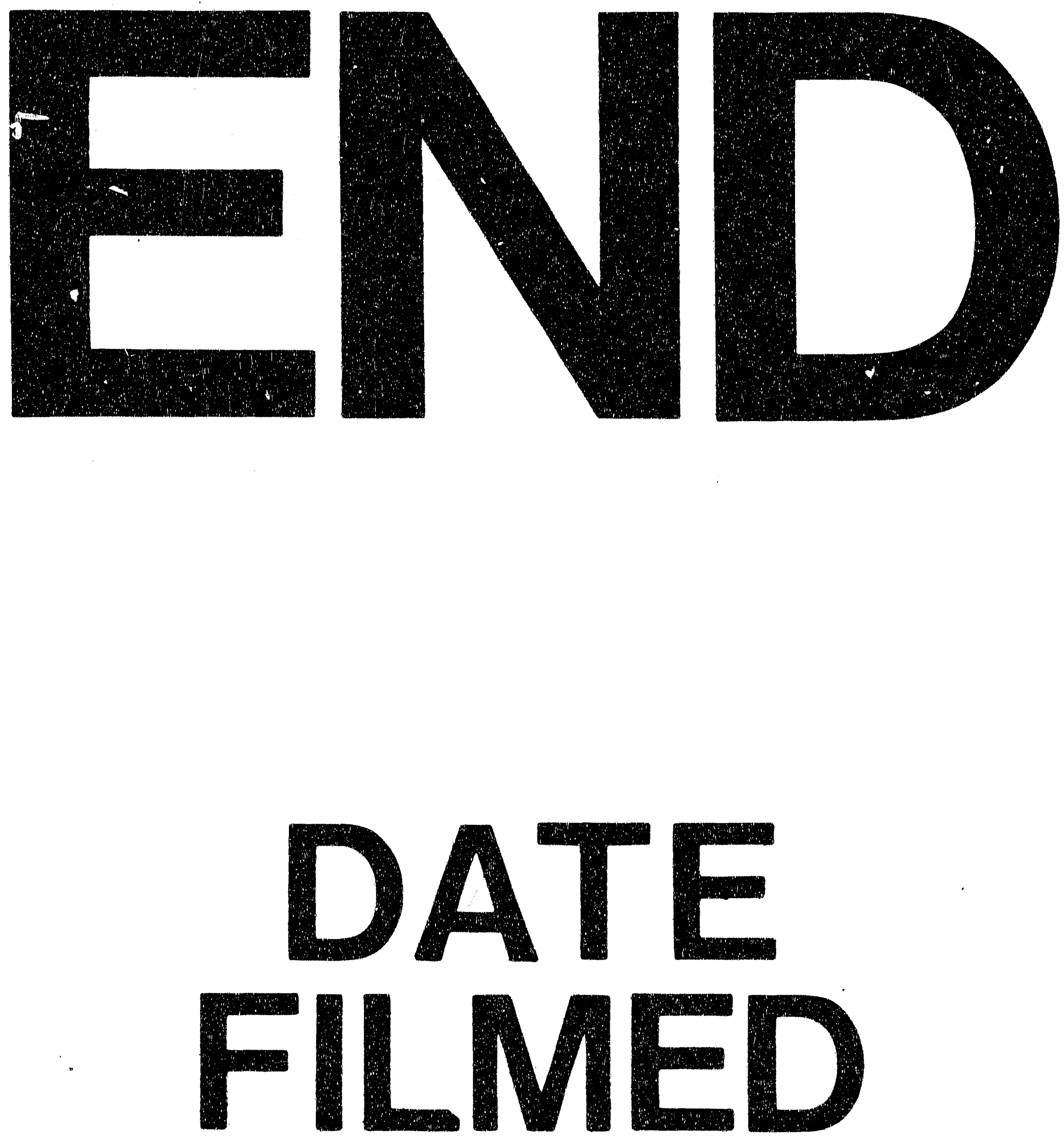

竞

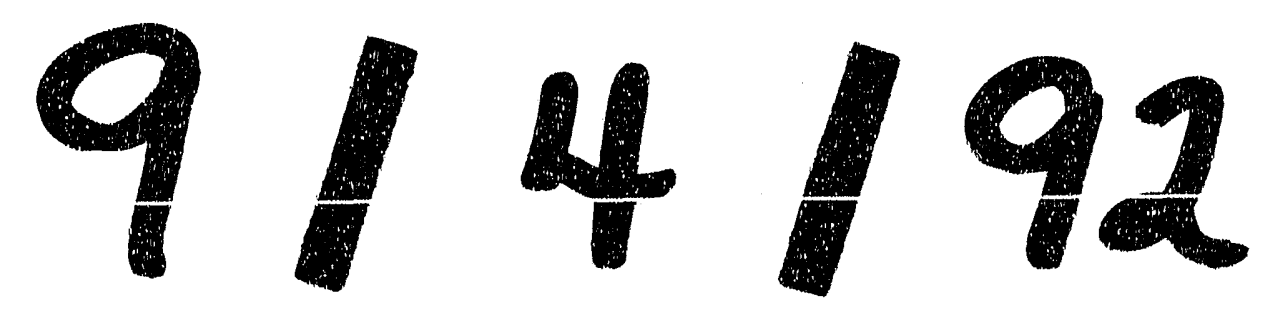


